\title{
UTILIZATION RATE OF DENTAL SERVICES IN THE ERA OF NATIONAL HEALTH INSURANCE IN PRATAMA CLINIC, CITY OF JEPARA
}

Erdianto Setya Wardhana*,Mohammad Yusuf**,Maila Samicha Salwa ***

${ }^{*}$ Departemen Ilmu Kesehatan Masyarakat Fakultas Kedokteran Gigi Universitas Sultan Agung Semarang ** Departemen Radiologi Fakultas Kedokteran Gigi Universitas Sultan Agung Semarang

*** Program Pendidikan Dokter Gigi Fakultas Kedokteran Gigi Universitas Sultan Agung Semarang

Correspondence: erdianto.wardhana@unissula.ac.id

\section{Keywords:}

Utilization rate, klinik pratama, Jaminan Kesehatan Nasional

\begin{abstract}
Background: The utilization rate is the use of dental and oral health which can be calculated using the number of National Healthcare Security (BPJS) patients per month compared to the number of BPJS participants multiplied by $100 \%$ Method: This study was an observational study used cross sectiona design and nominal data scale that produced quantitative data which was carried out by analysing the Pcare data started from March-August 2019 in eight primary clinics of Jepara City and District. Before conducted the study, Ethics Review No.098 / b. 1-KEPK / SA-FKG / VII / 2019 was done.

Result: The results of the utilization rate study based on the visit rates, Armina Pratama Clinic was $1.585 \%$, Multisari II Pratama Clinic was $0.665 \%$, Sentra Husada Pratama Clinic was $0.68 \%$, Jepara General Pratama Clinic was $2.329 \%$, Yasmin Medika Pratama Clinic was $2.173 \%$, Hanis Pratama Clinic was $0.752 \%$, Az-Zahra pratama clinic $2.945 \%$, and Armina Denta pratama clinic was $1.885 \%$.

Conclusion: In conclusion, the utilization rate based on pratama clinic visits in the city and the regency of Jepara was still in the low to the ideal category. Meanwhile, the utilization rate based on the referral numbers of pratama clinic in the city and the regency of Jepara was far from the standard value
\end{abstract}

\section{PENDAHULUAN}

Kesehatan merupakan salah satu faktor yang penting dalam kehidupan manuasia. Kesehatan gigi dan mulut sangat berpengaruh terhadap kesehatan tubuh seseorang. Di Indonesia kesehatan gigi dan mulut masyarakat tercatat masih cukup rendah, hal itu terjadi karena adanya beberapa faktor salah satunya adalah masalah biaya ${ }^{1}$. Untuk meminimalisir terjadinya peningkatan kasus penyakit gigi dan mulut, pemerintah berupaya untuk dalam mewujudkan sistem jaminan kesehatan bagi seluruh penduduk Indonesia (Universal Health Coverage). Sistem yang dimaksud adalah Sistem Jaminan Kesehatan Nasional (JKN) yang diselenggarakan oleh Badan
Penyelenggaraan Jaminan Sosial Kesehatan (BPJS Kesehatan) mulai 1 Januari 20142,3.

Program JKN ini dapat diterapkan pada fasilitas pelayanan kesehatan tingkat pertama yaitu klinik pratama. Dalam melakukan pelayanan kesehatan, Fasilitas Kesehatan Tingkat Pertama atau FKTP menggunakan sistem pembayaran yang disebut sebagai Kapitasi. Sistem Kapitasi merupakan salah satu metode pembayaran untuk jasa pelayanan kesehatan dimana pemberi pelayanan kesehatan (dokter atau rumah sakit) menerima sejumlah tetap penghasilan per peserta dan per periode waktu untuk pelayanan yang telah ditentukan ${ }^{4,5}$. 
Permasalahan sistem JKN yang sering muncul dalam pelayanan kesehatan gigi di Fasilitas pelayanan kesehatan pertama yaitu, permasalahan sistem kapitasi. Persoalan yang banyak dikeluhkan yaitu dana kapitasi yang di berikan BPJS kepada FKTP setiap bulan dirasa belum bisa memenuhi kebutuhan untuk membayar pemberi jasa kesehatan, sehingga FKTP hanya bisa memberikan pelayanan promotif dan preventif sedangkan masyarakat berharap bisa mendapatkan pelayanan kesehatan yang lengkap di FKTP. Permasalahan tersebut menyebabkan turunnya tingkat pemanfaatan pelayanan kesehatan (utilization rate) yang diterima oleh masyarakat di FKTP5,6.

Tujuan dari penelitian ini adalah untuk mengetahui gambaran utilization rate pelayanan kesehatan gigi dan mulut era jaminan kesehatan nasional (JKN) di klinik pratama poli gigi Kota dan Kabupaten Jepara.

\section{METODE PENELITIAN}

Metode penelitian yang digunakan adalah observasional deskriptif. Rancangan penelitian pada penelitian ini yaitu, cross sectional menggunakan skala data nominal dan menghasilkan data kuantitatif.

Sampel yang diambil peneliti berasal dari delapan Klinik Pratama poli gigi yang terdaftar dalam BPJS di Kota dan Kabupaten Jepara. Teknik yang digunakan yaitu, total sampling. Instrumen dalam penelitian ini yaitu checklist dari koding diagnosis dan perawatan yang telah di tetapkan permenkes. Penelitian ini telah mendapatkan Kaji Etik oleh Komite Etik FKG Unissula yaitu No.098/b.1-KEPK/SA-FKG/VII/2019. Data utilisasi diolah bedasarkan jumlah kepersertaan, angka kunjungan yang meliputi usia, jenis kelamin, diagnosis, serta tindakan perawatannya, dan angka rujukan. Setelah itu data di analisis dengan secara deskriptif dan ditampilkan dalam bentuk tabel dan diagram.

\section{HASIL PENELITIAN}

Penelitian ini dilakukan dengan cara mengambil data sekunder dari program Pcare di beberapa klinik pratama, yaitu klinik pratama Armina (A), klinik pratama Multisasri II (B), klinik pratama Sentra Husada (C), klinik pratama Umum Jepara (D), klinik pratama Yasmin Medika (E), klinik pratama Hanis (F), klinik pratama Az-Zahra (G), dan klinik pratama Armina Denta(H). Penelitian ini dilaksanakan pada bulan Agustus hingga September 2019 dan data-data yang diambil adalah data dari program Pcare di rentang waktu bulan Maret hingga Agustus 2019. Berikut ini adalah data yang telah diperoleh : 


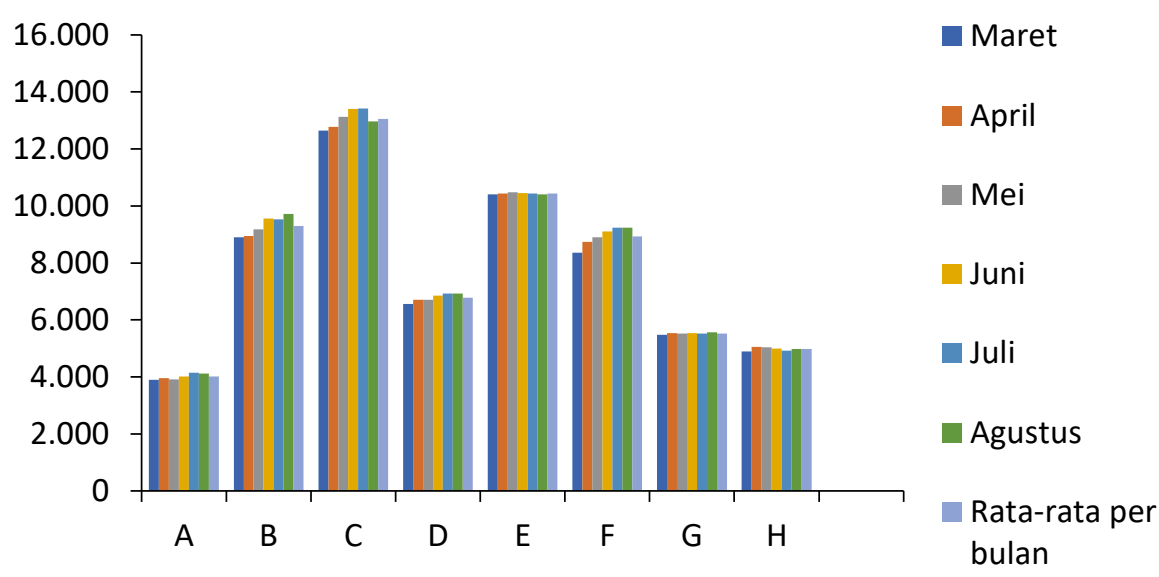

Gambar 1.1 Disribusi jumlah Kepesertaan BPJS di klinik pratama Kota dan Kabupaten Jepara bulan Maret hingga Agustus tahun 2019

Berdasarkan data di atas dapat dilihat bahwa jumlah kepesertaan BPJS yang selalu mengalami peningkatan setiap bulannya, tetapi tidak semua jumlah kepesertaan BPJS mengalami peningkatan setiap bulannya

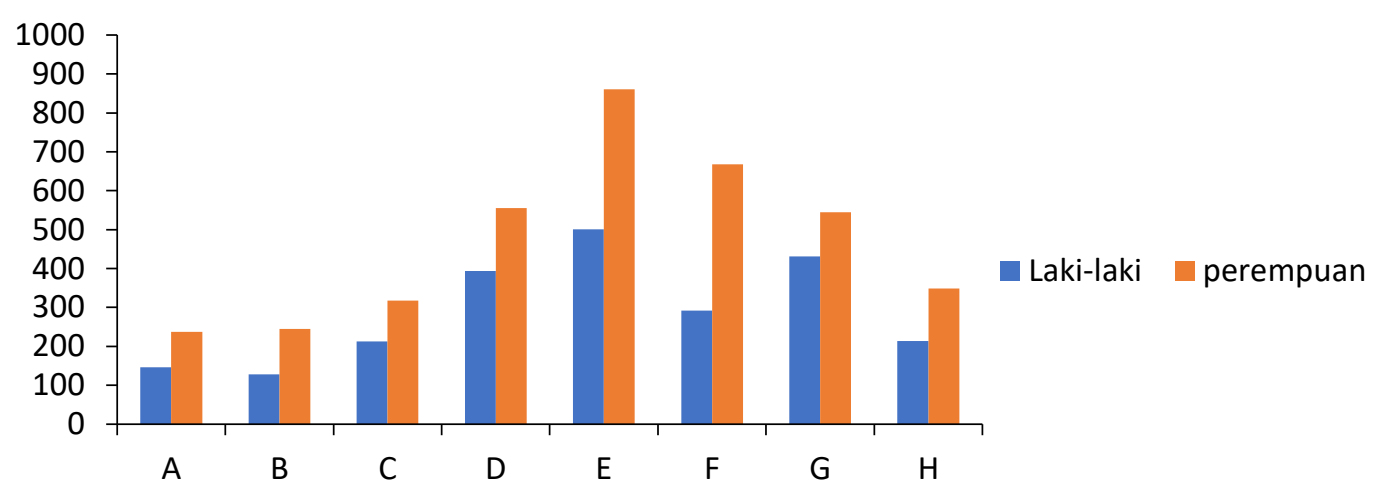

Gambar 1.2 Disribusi angka kunjungan pasien berdasarkan jenis kelamin

Berdasarkan data angka kunjungan pasien menurut jenis kelamin pada ke delapan klinik di atas menunjukan bahwa kunjungan pasien perempuan lebih banyak dari pada jumlah kunjungan pasien laki-laki 


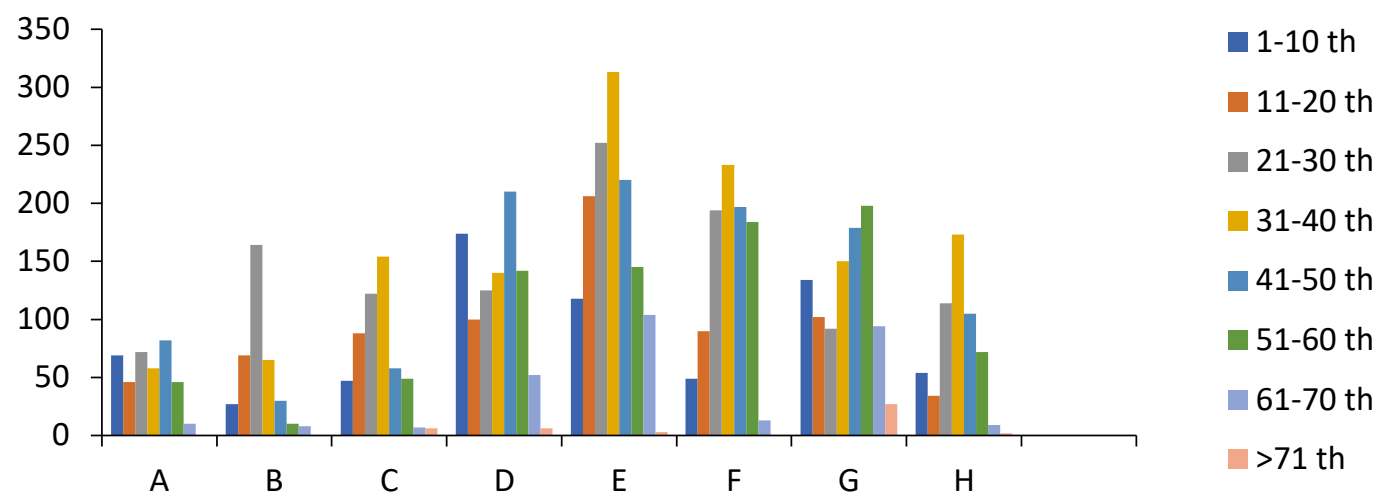

Gambar 1.3 Distribusi angka kunjungan pasien berdasarkan usia

Berdasarkan data kunjungan pasien menurut usia di atas di dapatkan bahwa jumlah kunjungan pasien berdasarkan usia jumlah kunjungan tertinggi berada di usia 31-40 tahun sebanyak 1268 pasien dan untuk jumlah kunjungan pasien berdasarkan usia terendah di usia $>71$ tahun yaitu 44 pasien

Tabel 1.1 Disribusi angka kunjungan pasien BPJS

\begin{tabular}{lllllllll}
\hline \multirow{2}{*}{ Bulan } & \multicolumn{7}{c}{ Klinik Pratama } \\
\cline { 2 - 9 } & $\mathrm{A}$ & $\mathrm{B}$ & $\mathrm{C}$ & $\mathrm{D}$ & $\mathrm{E}$ & $\mathrm{F}$ & $\mathrm{G}$ & $\mathrm{H}$ \\
\hline Maret & 50 & 53 & 104 & 129 & 295 & 188 & 195 & 108 \\
\hline April & 45 & 56 & 113 & 147 & 228 & 158 & 165 & 83 \\
\hline Mei & 74 & 59 & 95 & 184 & 161 & 140 & 153 & 69 \\
\hline Juni & 44 & 55 & 74 & 125 & 189 & 92 & 108 & 109 \\
\hline Juli & 86 & 84 & 72 & 214 & 263 & 198 & 200 & 93 \\
\hline Agustus & 84 & 66 & 73 & 150 & 225 & 184 & 155 & 101 \\
\hline
\end{tabular}

Berdasarkan data angka kunjungan pasien BPJS di poli gigi jumlah kunjungan terbanyak di urutan pertama ada di klinik pratama Yasmin Medika, urutan kedua ada di klinik pratama AzZahra dan di urutan ketiga ada di klinik pratama Hanis. Dan untuk angka kunjungan terendah terjadi di klinik pratama Multisari II. Berdasarkan jumlah kunjungan perbulan, angka kunjungan pasien terbanyak berada di bulan Maret sebanyak 295 pasien untuk klinik pratama Yasmin Medika.

Tabel 1.2 Disribusi angka rujukan

\begin{tabular}{|c|c|c|c|c|c|c|c|c|c|c|c|c|c|c|}
\hline \multirow{2}{*}{ Bulan } & \multicolumn{14}{|c|}{$\begin{array}{c}\text { Klinik Pratama } \\
\% \text { dan jumlah kunjungan }\end{array}$} \\
\hline & & & B & & & & D & & E & & 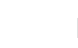 & & $G$ & $\mathrm{H}$ \\
\hline Maret & 4 & 50 & 1,88 & 53 & 2,88 & 104 & 1,55 & 129 & 3,72 & 295 & 1,06 & 188 & -195 & $\begin{array}{ll}10,18 & 108\end{array}$ \\
\hline
\end{tabular}




\begin{tabular}{lcccccccccccccccc}
\hline April & 13,3 & 45 & 1,78 & 56 & 10,61 & 113 & 2,27 & 147 & 0,43 & 228 & 1,89 & 158 & - & 165 & - & 83 \\
\hline Mei & 6,75 & 74 & - & 59 & 10,52 & 95 & 3,26 & 184 & 3,72 & 161 & - & 140 & - & 153 & 8,69 & 69 \\
\hline Juni & 2,27 & 44 & 1,81 & 55 & 12,16 & 74 & 2,4 & 125 & 1,05 & 189 & - & 92 & - & 108 & 6,42 & 109 \\
\hline Juli & 2,32 & 86 & 4,76 & 84 & 12,5 & 72 & 0,93 & 214 & 3,42 & 263 & 2,52 & 198 & - & 200 & 2,15 & 93 \\
\hline Agustus & 7,14 & 84 & 5,54 & 66 & 10,95 & 73 & 0,67 & 150 & 0,44 & 225 & 3,80 & 184 & - & 155 & 3,29 & 101 \\
\hline
\end{tabular}

Berdasarkan data prosentase angka rujukan pasien BPJS bahwa dari delapan klinik pratama memiliki prosentase angka rujukan, dan ada beberapa bulan klinik yang tidak melakukan rujukan.

Table 1.3 Disribusi kunjungan pasien berdasarkan diagnosis

\begin{tabular}{lllllllllll}
\hline \multirow{2}{*}{ NO } & Kode & \multicolumn{7}{c}{ Klinik Pratama } & \multirow{2}{*}{ Jumlah } \\
\cline { 2 - 9 } & Diagnosis & A & B & C & D & E & F & G & H & \\
\hline 1 & K00 & 16 & 3 & 47 & 32 & 56 & 37 & - & 22 & 213 \\
\hline 2 & K01 & 14 & 20 & 22 & 21 & 17 & 20 & - & 6 & 120 \\
\hline 3 & K02 & 31 & 54 & 26 & 41 & 163 & 157 & - & 34 & 506 \\
\hline 4 & K03 & 6 & 6 & 1 & 15 & 116 & 156 & - & 11 & 311 \\
\hline 5 & K04 & 139 & 230 & 262 & 223 & 409 & 294 & - & 233 & 1790 \\
\hline 6 & K05 & 41 & 28 & 51 & 73 & 241 & 232 & 976 & 50 & 1692 \\
\hline 7 & K06 & - & - & - & - & - & - & - & - & - \\
\hline 8 & K07 & - & - & 3 & 9 & - & 6 & - & - & 18 \\
\hline 9 & K08 & 44 & 2 & 17 & 14 & 20 & 13 & - & 9 & 119 \\
\hline 10 & K09 & - & - & - & - & - & - & - & - & - \\
\hline 11 & K10 & - & - & - & - & - & - & - & - & - \\
\hline 12 & K11 & - & - & - & - & - & - & - & - & - \\
\hline 13 & K12 & - & 1 & - & 5 & 6 & 2 & - & - & 14 \\
\hline 14 & K13 & - & - & - & - & - & - & - & - & - \\
\hline 15 & S02 & 3 & 4 & 5 & 2 & 29 & 18 & - & 9 & 70 \\
\hline & JUMLAH & 294 & 348 & 434 & 502 & 1057 & 935 & 976 & 374 \\
\hline & & & & & & & & & \\
\hline
\end{tabular}

Tabel 1.3 menunjunkan bahwa terdapat 6 daignosis terbanyak yaitu K04 (Hiperemi pulpa, pulpitis akut, Pulpitis reversible) sebanyak 1790, K05 (Gingivitis dan Penyakit periodontal) sebanyak 1692, K02 (Gigi Impaksi) sebanyak 506, K03 (Atrisi, erosi, abrasi, dentin sensitive, Stain) sebanyak 311, K00 (Presistensi desidui) sebanyak 213.

Tabel 1.4 Distribusi kunjungan pasien berdasarkan tindakan perawatan

\begin{tabular}{lcccccccccc}
\hline \multirow{2}{*}{ No } & Jenis & \multicolumn{1}{c}{ Klinik Pratama } \\
\cline { 3 - 11 } & Tindakan & A & B & C & D & E & F & G & H & \\
\hline 1 & Medikasi & 85 & 101 & 183 & 86 & 318 & 168 & 976 & 83 & 2000 \\
\hline
\end{tabular}




\begin{tabular}{|c|c|c|c|c|c|c|c|c|c|c|}
\hline 2 & Tumpat GIC & 36 & 34 & 58 & 148 & 274 & 244 & - & 74 & 868 \\
\hline 3 & Exodonsi & 73 & 19 & 80 & 104 & 111 & 210 & - & 73 & 670 \\
\hline 4 & Devitalisasi & 38 & 44 & 73 & 52 & 73 & 65 & - & 38 & 383 \\
\hline 5 & Cavit & 1 & - & 7 & 27 & 60 & 209 & - & 12 & 316 \\
\hline 6 & Dressing & - & 47 & 44 & 30 & 5 & 152 & - & 10 & 288 \\
\hline 7 & Konsultasi & 21 & 17 & 30 & 29 & 28 & 83 & - & 13 & 221 \\
\hline 8 & Trepanasi & 7 & 4 & 19 & 25 & 55 & 2 & - & 60 & 172 \\
\hline 9 & Mumifikasi & - & 16 & 15 & 29 & - & 44 & - & - & 104 \\
\hline 10 & Scalling & 3 & 15 & 8 & 11 & 9 & 31 & - & 12 & 89 \\
\hline 11 & Observasi & 7 & 1 & - & - & - & - & - & 71 & 79 \\
\hline 12 & Cetak rahang & 4 & 1 & - & 2 & 13 & 4 & - & 44 & 68 \\
\hline 13 & Tumpatan RK & - & 22 & 4 & 6 & - & 27 & - & 1 & 60 \\
\hline 14 & Obturasi & 1 & - & 21 & - & - & - & - & - & 22 \\
\hline 15 & Pulp Capping & - & - & - & - & - & 21 & - & - & 21 \\
\hline 16 & PSA & - & - & - & - & - & - & - & 10 & 10 \\
\hline 17 & Insersi & - & - & - & 1 & 2 & 6 & - & 3 & 12 \\
\hline 18 & Spooling & - & 5 & - & - & - & - & - & - & 5 \\
\hline & JUMLAH & 276 & 326 & 543 & 550 & 948 & 1266 & 976 & 481 & \\
\hline
\end{tabular}

Berdasarkan tabel di atas terdapat 5 jenis tindakan terbanyak yaitu Medikasi sebanyak 2000 tindakan, Tumpatan GIC sebanyak 868 tindakan, Exodonsi sebanyak 670 tindakan, Devitalisasi 383 tindakan, Cavit 316 tindakan.

Tabel 1.5 Nilai Utilization rate berdasarkan angka kunjungan

\begin{tabular}{|c|c|c|c|c|c|c|c|c|c|}
\hline \multirow{2}{*}{ No } & \multirow{2}{*}{ Bulan } & \multicolumn{8}{|c|}{ Utilization rate angka kunjungan(\%) } \\
\hline & & A & $\mathrm{B}$ & C & $\mathrm{D}$ & $E$ & $\mathrm{~F}$ & $\mathrm{G}$ & $\mathrm{H}$ \\
\hline 1 & Maret & 1,281 & 0,595 & 0,822 & 1,966 & 2,834 & 2,247 & 3,564 & 2,208 \\
\hline 2 & April & 1,137 & 0,626 & 0,884 & 2,191 & 2,185 & 1,806 & 2,981 & 1,643 \\
\hline 3 & Mei & 1,893 & 0,642 & 0,723 & 2,744 & 1,536 & 1,574 & 2,771 & 1,370 \\
\hline 4 & Juni & 1,095 & 0,575 & 0,552 & 1,824 & 1,808 & 1,009 & 1,951 & 2,179 \\
\hline 5 & Juli & 2,072 & 0,881 & 0,536 & 3,087 & 2,520 & 2,143 & 3,623 & 1,887 \\
\hline 6 & Agustus & 2,036 & 0,679 & 0,563 & 2,164 & 2,160 & 1,992 & 2,783 & 2,025 \\
\hline & $\begin{array}{l}\text { rata per } \\
\text { ulan }\end{array}$ & 1,585 & 0,666 & 0,68 & 2,329 & 2,173 & 1,795 & 2,945 & 1,885 \\
\hline
\end{tabular}

Hasil perhitungan Utilization rate berdasarkan angka kunjungan jumlah tertinggi kujungan pasien BPJS di poli gigi pada bulan Maret,April, Mei terjadi pada klinik pratama Az-Zahra dengan angka 3,564\%, 2,981\%, dan 2,771\%. Pada bulan Juni nilai tertinggi terdapat pada 
klinik pratama Armina Denta sebesar 2,179\%. Dan untuk bulan Juli hingga Agustus pada klinik pratama Az-Zahra menunjukan nilai tertinggi sebesar 3,623\% dan 2,783\%.

Tabel 1.6 Nilai Utilization rate berdasarkan angka rujukan

\begin{tabular}{cccccccccc}
\hline \multirow{2}{*}{ No } & \multirow{2}{*}{ Bulan } & \multicolumn{8}{c}{ Utilization rate angka rujukan(\%) } \\
\cline { 3 - 10 } & & A & B & C & D & E & F & G & H \\
\hline 1 & Maret & 4 & 1,88 & 2,88 & 1,55 & 3,72 & 1,06 & - & 10,18 \\
\hline 2 & April & 13,3 & 1,78 & 10,61 & 2,72 & 0,43 & 1,89 & - & - \\
\hline 3 & Mei & 6,75 & - & 10,52 & 3,26 & 3,72 & - & - & 8,69 \\
\hline 4 & Juni & 2,27 & 1,81 & 12,16 & 2,4 & 1,05 & - & - & 6,42 \\
\hline 5 & Juli & 2,32 & 4,76 & 12,5 & 0,93 & 3,42 & 2,52 & - & 2,15 \\
\hline 6 & Agustus & 7,14 & 4,54 & 10,95 & 0,65 & 0,44 & 3,80 & - & 3,96 \\
\hline $\begin{array}{c}\text { Rata-rata per } \\
\text { bulan }\end{array}$ & 5,96 & 2,47 & 9,93 & 1,91 & 2,13 & 1,54 & - & 5,23 \\
& & & & & & & & \\
\hline
\end{tabular}

Hasil penghitungan Utilization rate angka rujukan di klinik pratama Armina nilai tertinggi sebesar $13,3 \%$, klinik pratama Multisari II memiliki nilai Utilization rate angka rujukan sebesar $4,76 \%$, Utilization rate angka rujukan klinik pratama Sentra Husada nilai tertinggi 12,16 \%, Utilization rate angka rujukan klinik pratama Umum Jepara Nilai tertinggi 3,26\%, Utilization rate angka rujukan klinik pratama Yasmin Medika nilai tertinggi di bulan 3,72\%, Utilization rate angka rujukan klinik pratama Hanis nilai tertinggi 3,80\%, Utilization rate angka rujukan klinik pratama Az-Zahra tidak melakukan rujukan ke FKTL, Utilization rate angka rujukan klinik pratama Armina Denta nilai tertinggi 10,18\% .

\section{DISKUSI}

Data utilization rate berdasarkan angka kunjungan atau rujukan pasien dapat di ketahui dengan rumus jumlah kunjungan atau rujukan pasien BPJS poli gigi dari masing-masing klinik dibagi dengan jumlah peserta BPJS pada bulan tersebut dikalikan 100\% (Tabel 1.5 dan 1.6).

Gambaran Utilization rate di klinik pratama Kota dan Kabupaten Jepara didapatkan hasil kategori rendah hingga ideal (Tabel 1.5 dan 1.6) $\mathrm{g}$. Menurut Dewanto dan Lestasri (2014) nilai Utilization rate yaitu $2 \%$ dengan kategori ideal. Sedangkan untuk dibawah $2 \%$ nilai Utilization rate masuk dalam kategori rendah, dan apabila nilai utilitasnya di atas $3 \%$ memiliki kategori tinggi.
Perbedaan nilai utilisasi terjadi karena jumlah peserta BPJS di masing-masing Klinik Pratama berbeda, sehingga hal itu dapat mempengaruhi nilai utilization rate ${ }^{5,7}$.

Nilai utilisasi yang rendah kemungkinan terjadi karena pengetahuan peserta yang masih rendah mengenai program JKN, sehingga membuat peserta tidak mengetahui bagaimana memanfaatkan program tersebut dalam pelayanan kesehatan ${ }^{8}$. Nilai utilisasi yang tinggi akan menyebabkan tidak seimbangnya resiko dan pembiayaan dalam pelayanan kesehatan gigi dan mulut oleh dokter gigi sehingga mengakibatkan kerugian dari dokter gigi 5 . 
Beberapa faktor penyebab dalam pemanfaatan pelayanan kesehatan yaitu akses geografis, jenis kelamin dan usia ${ }^{1}$. Menurut Sholihin \& Thabrany (2014) terdapat beberapa faktor dalam pemanfaatan pelayanan kesehatan yaitu motivasi dan kebutuhan perawatan kesehatan gigi dan mulut. Meskipun seseorang mengalami gangguan dalam kesehatan gigi dan mulut apabila tidak memiliki motivasi untuk sembuh maka orang tersebut tidak akan melakukan pengobatan. Demikian juga sebaliknya, seseorang ketika mengalami gangguan kesehatan gigi dan mulut tetapi tidak ada semangat untuk sembuh maka orang tersebut tidak akan melakukan pengobatan ${ }^{8}$.

Angka Utilization Rate rujukan di klinik pratama Kota dan Kabupaten Jepara masih jauh dari nilai standar maksimal rujukan yaitu $15 \%{ }^{9}$. Klinik pratama merupakan salah satu gate-keeper yang mengatur sistem rujukan, yang dapat mengurangi atau menapis kunjungan pasien ke Fasilitas Kesehatan Tingkat Lanjutan. Klinik pratama dapat memberikan rujukan apabila pasien memerlukan fasilitas pelayanan yang tidak dapat diberikan di klinik pratama, hal itu terjadi karena keterbatasan fasilitas pelayanan dan ketenagaan. Implementasi gate-keeper dalam menjalankan tugasnya sebagai FKTP meliputi kredensialing dan re-kredensialing, dan penguat fungsi pokok yang terdiri dari kontak pertama, pelayanan yang berkelanjutan, pelayanan paripurna, pelayanan koordinasi, meningkatkan kompetensi untuk paramedis dan tenaga medis, serta mengendalikan mutu dan biaya. Syarat utama agar klinik dapat bergabung dengan BPJS yaitu dengan melakukan kredensialing dan re-kredensialing, dilanjukan ke peningkatkan kompetensi FKTP yang meliputi, kompetensi penunjang dan empat fungsi pokok. Apabila fungsi pokok telah berjalan dengan optimal maka kendali mutu dan biaya akan berjalan dengan baik ${ }^{5}$
Dalam melakukan penelitian ini, peneliti mengalami kendala seperti kurangnya sosialisasi program Pcare kepada dokter gigi dan petugas yang menginput data. Hal itu sesuai dengan penelitian Nuryati dkk (2016) petugas yang menginput data mengalami kesulitan, karena dalam penginputan data diagnosis harus menggunakan kode diagnosis ${ }^{10}$.

\section{KESIMPULAN}

Dari data yang didapatkan peneliti, dapat disimpulkan bahwa Gambaran utilization rate Pelayanan Kesehatan Gigi dan Mulut di klinik pratama Kota dan Kabupaten Jepara masih terdapat beberapa klinik pratama dalam kategori rendah. Hal ini terbukti dari perhitungan rumus utilization rate rata-rata nilai utilisasi dari kedelapan klinik pratama tersebut $<3 \%$ dengan kategori underideal utilization.

\section{UCAPAN TERIMAKASIH}

Terima kasih kami sampaikan kepada Fakultas Kedokteran Gigi Unissula dan LPPM Unisversitas Islam Sultan Agung yang telah banyak membantu dan memberikan fasilitas sehingga penelitian ini bisa berjalan dengan baik

\section{DAFTAR PUSTAKA}

1. Tasya N, Andriany P, Herwanda. Faktor-Faktor Yang Berhubungan Dengan Pemanfaatan Pelayanan Kesehatan Gigi Dan Mulut di Rumah Sakit Gigi Dan Mulut (RSGM) Universitas Syiah Kuala Banda Aceh. J Caninus Dent. 2016;1(November):54-62.

2. Irwandy I. Kajian Literature: Evaluasi Pelaksanaan Program Jaminan Kesehatan Nasional di Indonesia. J Kebijak Kesehat Indones JKKI [Internet]. 2016;5(3):110-4. Available from: https://jurnal.ugm.ac.id/jkki/article/view/30650

3. Kesehatan B. Panduan Praktik Pelayanan Gigi \& Prothesa Gigi. 2014;

4. Permenkes. Peraturan menteri Kesehatan Republik Indonesia Nomor 69 Tahun 2013 tentangStandar Tarif Pelayanan Kesehatan Pada Fasilitas Kesehatan Tingkat Pertama Dan 
Fasilitas Kesehatan Tingkat Lanjutan Dalam Penyelenggaraan Program Jaminan Kesehatan. In 2013.

5. Iwan Dewanto dan NIL. Panduan Pelaksanaan Pelayanan Kedokteran Gigi dalam Sistem Jaminan Kesehatan Nasional. In: Panduan Pelaksanaan Pelayanan Kedokteran Gigi dalam Sistem Jaminan Kesehatan Nasional. 1st ed. Jakarta Timur: Pengurus Besar Persatuan Dokter Gigi Indonesia; 2014. p. 1-44.

6. Fitrianeti D, Waris L, Yulianti A. Penganggaran dan Penerimaan Dana Kapitasi Program JKN di Daerah Terpencil Kabupaten Kepulauan Mentawai Implementation of Breaching And Acceptance Of Health Capitation Funds National Health Care Program In Remote Areas Of Distric Mentawai Islands. J Penelit dan Pengemb Pelayanan Kesehatan. 2017;1(2):92-101.

7. Logen Y, Balqis, Darmawansyah. Factor Relate to Usage With Health Service of Trash Picker in Tamangapa Landfill. Kesehat Masy Univ Hasanuddin [Internet]. 2015;6-7. Available from: http://repository.unhas.ac.id/bitstream/handle/1 23456789/14461/Yustina Logen K1111408.Pdf?Sequence $=1$

8. Muhamad Solihin HT. Pemanfaatan Pelayanan Kesehatan Oleh Peserta Jaminan Kesehatan Nasional Muhamad Solihin , Hasbullah Thabrany Abstrak Abstract Utilization Of Health Services by The Nasional Health Insurance ( JKN ) Participants at Puskesmas Cijeruk in Bogor District Janua. FKM UI. 2014;

9. Chabibah N, Chalidyanto D. Analisis Rasio Rujukan Puskesmas Berdasarkan Kemampuan Pelayanan Puskesmas. $J$ Adm Kesehat Indones. 2014;2(3):159-68.

10. Nuryati, Budi SC, Rokhman N. Kendala Pelaksanaan Program JKN Terkai Penerimaan Pasien, Pengolahan Data Medis, Pelaporan, dan Pendanaan JKN DI Puskesmas Gondokusumi II Yogyakarta. J Manaj Inf Kesehat Indones. 2016;4(1). 